\title{
Inference about Monophyly of the Family Oedipodidae and the Classification of Subfamilies Based on 16S rDNA Sequences
}

\author{
Dian-Feng Liu and Guo-Fang Jiang ${ }^{*}$
}

\author{
Jiangsu Key Laboratory for Biodiversity and Biotechnology, College of Life Sciences, Nanjing Normal \\ University, Nanjing 210023, China
}

\begin{abstract}
Most of grasshoppers in the family Oedipodidae are the famous agriculture pests in China. However monophyly and the relationships among the subfamilies within this family are unclear up to now. Here the phylogeny of the Oedipodidae was reconstructed based on 16S rDNA sequence fragments by using Mekongiella kingdoni and Atractomorpha sinensis as outgroups under weighted MP, NJ and Bayesian criteria. The 408 bp fragments of mitochondrial 16S rRNA gene were sequenced for 15 species from 4 subfamilies of the family Oedipodidae, and the homologous sequences of other 15 species of grasshoppers were downloaded from the GenBank data library. The numbers of transitions and transversions among pairwise comparisons of the $16 \mathrm{~S}$ fragments were respectively plotted against percentage sequence differences. Saturation of transitions was discovered, and transversions were not saturated with the increase of percentage sequence difference in the plots. All the individuals of the Oedipodidae excluding Trilophidia annulata were gathered together in the three trees. Our results are very different from the traditionary taxonomy of the Oedipodidae including 4 subfamilies. The Bryodemellinae is not supported as a subfamily, and neither Locustinae nor Oedipodinae are supported as a monophyletic group in this study.
\end{abstract}

Keywords: Oedipodidae, 16S rDNA, monophyly, subfamily.

\section{INTRODUCTION}

The family Oedipodidae is one of the largest families in the super family Acridoidea, including 137 described species of 38 genera of 4 subfamilies in China. The Oedipodidae species are largely distributed in the Palaeoacrtic regionwith a few species distributed in the Oriental region [1,2]. Historically Locusta migratoria manilensis of the Oedipodidae was a famous agriculture pest in China. Because the Oedipodidae is a larger group in the Acridoidea, and the phylogenetic study on them is crucial for understanding the phylogeny of Acridoidea, even to the Caelifera.

The taxonomic position of the Oedipodidae has been revised several times. It is usually recognised as a family of the Acridoidea by Chinese specialists [2,3], while classified as a subfamily by other specialists [47]. Phylogenetic analysis did not support the monophyly of Catantopidae, Arcypterdae, Gomphoceridae and Acrididae in our previous study based on 18S rDNA [8], but unfortunately it did not resolve the monophyly of the Oedipodidae.

In order to identify the monophyly of the Oedipodidae and to obtain a clear understanding of the relationships among the four subfamlies of the Oedipodidae, we utilized partial sequences of the mitochondrial 16S rDNA to reconstruct the phylogeny

*Address correspondence to this author at the Jiangsu Key Laboratory for Biodiversity and Biotechnology, College of Life Sciences, Nanjing Normal University, No. 1 Wenyuan Road, Qixia District, Nanjing 210023, China; Tel/Fax: 86-25- 86307256; E-mail: cnjgf1208@163.com of the Oedipodidae. The 16S rDNA is one of the most comprehensively studied genes in insects [9], and generally considered well to effectively research organism divergences before 50 millions of years [10]. Fifteen species from the Oedipodidae were sequenced in this study. The $16 \mathrm{~S}$ rDNA sequences of other fifteen grasshoppers were download from GenBank for comparisons, in which six species belongs to the Oedipodidae. In the thirty grasshoppers studied, Mekongiella kingdoni of the Chrotogonidae and Atractomorpha sinensis of the Pyrgormorphidae were chosen as the outgroups.

\section{MATERIALS AND METHODS}

\subsection{Samples and DNA Extraction}

The 15 species of grasshoppers used in this study were collected from China (Table 1). The individuals of alive grasshoppers were stored in absolute ethanol. The species was identified by using Xia's taxonomic system [11]. Total genomic DNA was extracted from legs of single grasshopper by using a simple proteinase K/SDS method.Tissue was ground and incubated in $0.02 \mathrm{M}$ Tris $\mathrm{HCl}(\mathrm{pH} 8), 0.01 \mathrm{M}$ EDTA, $0.5 \%$ SDS, and $50 \mathrm{mg} / \mathrm{mL}$ of Proteinase $\mathrm{K}$ overnight at $50^{\circ} \mathrm{C}$. This mixture was extracted with phenol/chloroform, and finally the DNA samples were precipitated with ethanol as described by [12].

\subsection{PCR Amplification}

The primers, which were used for amplification in this study, were according to Simon et al. [13]. For the 
Table 1: Original of the Researched Sanples

\begin{tabular}{|c|c|c|c|c|c|c|}
\hline Subfamily & Species & Collection site & Collector & Voucher & Dates & $\begin{array}{c}\text { Accession of } \\
\text { GenBank }\end{array}$ \\
\hline \multirow{3}{*}{ Locustinae } & Locusta migratoria manilensis & Laibin, Guangxi & JGF & H5042 & 2000. 7 & \\
\hline & Pternoscirta sauteri & Tiane, Guangxi & JGF & H5011 & 2002. 4 & \\
\hline & Pternoscirta pulchripes & Fangcheng, Guangxi & JGF & H5012 & 2002. 4 & \\
\hline \multirow{7}{*}{ Oedipodinae } & Trilophidia annulata & longzhou, Guangxi & LJW & H5281 & 2002. 7 & \\
\hline & Epacromius coerulies & Ningxian, Gansu & LDF & H5311 & 2004. 8 & \\
\hline & Oedaleus decorus asiaticus & Diebu, Gansu & LDF & H5192 & 2004. 8 & \\
\hline & Celes akitanus & Jilin & RBZ & H5231 & 2003. 8 & \\
\hline & Parapheurus alliaceus & Jilin & RBZ & H5091 & 2003. 8 & \\
\hline & Sphingonotus salinus & Diebu, Gansu & LDF & H5332 & 2004.8 & \\
\hline & Sphingonotus ningsianus & Wuwei, Gansu & LDF & H5331 & 2004. 8 & \\
\hline \multirow{2}{*}{ Bryodemellinae } & Bryodemilla diamesum & Lasa, Xizang & JGF & H5051 & 2002. 7 & \\
\hline & Bryodemella xizangensis & Lasa, Xizang & JGF & H5071 & 2002. 7 & \\
\hline \multirow{3}{*}{ Bryodeminae } & Bryodema luctuosum indum & Qingtongxia, Ningxia & LDF & H5072 & 2004. 8 & \\
\hline & Bryodema gansuensis & Diebu, Gansu & LDF & $\mathrm{H} 5074$ & 2004. 8 & \\
\hline & Angaracris rhodopa & Xining, Qinghai & JGF & H5082 & 2003. 7 & \\
\hline
\end{tabular}

Note. Collector abbreviations: JGF, Jiang GuoFang; LDF, Liu DianFeng; LJW, Liu JianWen; RBZ, Ren BingZhong.

LSU rRNA fragment, primers are LR-N-13398 5'CGCCTGTTTAACAAAAACAT-3' and LR-J-12887 5'CCGGTCTGAACTCAGATCACGT-3'. The primers were synthesized by Shanghai Sangon Biological Engineering Technology \& Service Co., Ltd (Shanghai, China).

PCRs were $30 \mu \mathrm{L}$ in volume and contained $10 \mathrm{~m}$ $\mathrm{moL} / \mathrm{L}$ Tris (pH8.3), $50 \mathrm{~m} \mathrm{moL} / \mathrm{L} \mathrm{KCL}, 0.01 \%$ TritonX$100,1.5 \mathrm{~m} \mathrm{moL} / \mathrm{L} \mathrm{MgCl}_{2}, 0.2 \mathrm{~m} \mathrm{moL} / \mathrm{L}$ dNTP, $0.4 \mathrm{~m}$ moL/L primers, 1.0 unit of Taq-polymerase and $1 \mu \mathrm{L}$ template DNA (10-25ng). Amplifications were performed under the following conditions: an initial denaturation step of $5 \mathrm{~min}$ at $94^{\circ} \mathrm{C} ; 30$ cycles of $30 \mathrm{~s}$ $94^{\circ} \mathrm{C}, 40 \mathrm{~s} 48^{\circ} \mathrm{C}, 30 \mathrm{~S} 72^{\circ} \mathrm{C}$, and a final extension step at $72^{\circ} \mathrm{C}$ for $10 \mathrm{~min}$.

Products of successful PCR amplifications were purified using a GeneClean III kit (Anachem, USA), following the protocol in the manual. Purified product were sequenced by Shanghai United Gene Company (Shanghai, China). Both strands of the 16S rDNA sequences were sequenced for each sample.

\subsection{Data Analysis}

The $16 \mathrm{~S}$ rDNA sequences of other 15 grasshoppers were download from GenBank for comparison, among them six species belongs to the Oedipodidae (Table 2).
All sequences were aligned using Clustal X [14] with parameters set to default. Alignments were improved by comparison to secondary structures and regions of uncertain alignment were omitted from subsequent analyses. In order to examine our 16S rDNA sequences for saturation, we plotted the uncorrected pairwise genetic distance ( $p$-distance) versus the absolute number oftransitions (TS) and absolute number of transversions (TV) among all taxa. Nucleotide variation and substitution patterns were examined using the software package MEGA6.0 [15] based on the Tamura-Nei model. We used three different types of phylogenetic analyses, neighbourjoining (NJ), maximum- parsimony (MP) and Bayesian inference. NJ and MP analyses were conducted using PAUP4.0b10 [16], Bayesian inference was used MrBayes3_0b4 [17]. Trees saved below the burn-in generation were discarded from the set of saved trees, and a majority rule consensus of the remaining trees were calculated in Mrbayes3_0b4, providing posterior probabilities for clades.

Mekongiella kingdoni and Atractomorpha sinensis were chosen as the outgroups in our analyses. For the $\mathrm{NJ}$ analysis, we selected the Tamura-Nei model. Branch support was assessed for all topologies using 1000 bootstrap replications. For the parsimony analyses, we performed a heuristic search using 
Table 2: GenBank Sequences Data Used in this Study

\begin{tabular}{|c|c|c|c|c|c|}
\hline Families & Subfamilies & Species & Number & Reference & $\begin{array}{c}\text { Accession of } \\
\text { GenBank }\end{array}$ \\
\hline \multirow{6}{*}{ Oedipodidae } & \multirow{2}{*}{ Locustinae } & locusta migrator & $\mathrm{H} 5 \mathrm{f}$ & Flook et al., 1994 & NC_001712 \\
\hline & & Gastrimargus marmoratus & h5031 & Jiang and Liu, 2004 & AY566264 \\
\hline & \multirow{4}{*}{ Oedipodinae } & Oedipoda coerulescens & $\mathrm{H} 5 \mathrm{~h}$ & Flook and Rowell, 1997 & Z93293 \\
\hline & & Aiolopus thalassinus & $\mathrm{H} 5 \mathrm{I}$ & Rowell and Flook, 2003 & AY352428 \\
\hline & & Sphingonotus haitensis & $\mathrm{H} 5 \mathrm{~s} 1$ & Rowell and Flook, 2003 & AY352436 \\
\hline & & Sphingonotus fuscoirroratus & $\mathrm{H} 5 \mathrm{~s} 2$ & Rowell and Flook, 2003 & AY352434 \\
\hline \multirow{2}{*}{ Catantopidae } & Catantopinae & Xenocatantops humilis & $\mathrm{H} 4822$ & Jiang and Liu, 2004 & AY566258 \\
\hline & Cytacanthacridinae & Chondracris rosea rosea & H4651 & Jiang and Liu, 2004 & AY566262 \\
\hline \multirow{2}{*}{ Arcypteridae } & \multirow{2}{*}{ Arcypterinae } & Chorthippus intermedius & $\mathrm{H} 6 \mathrm{~d}$ & Yin, et al., 2003 & AY379750 \\
\hline & & Arcyptera fusca & $\mathrm{H} 6 \mathrm{w}$ & Flook and Rowell, 1997 & Z93286 \\
\hline Gomphoceridae & Gomphoceriae & Dasyhippus peipingensis & $\mathrm{H} 7 \mathrm{~b}$ & Yin, et al., 2003 & AY379751 \\
\hline \multirow{2}{*}{ Acrididae } & \multirow{2}{*}{ Acridinae } & Acrida cinerea & $\mathrm{H} 8 \mathrm{z}$ & Yin, et al., 2003 & AY379748 \\
\hline & & Acrida turrita & $\mathrm{H} 8 \mathrm{n}$ & Flook et al., 1999 & Z97612 \\
\hline Pyrgormorphidae & Atractomorphinae & Atractomorpha sinensis & $H 3 d$ & Yin et al., 2003 & AY379746 \\
\hline Chrotogonidae & Mekongiellinae & Mekongiella kingdoni & $\mathrm{H} 2 \mathrm{j}$ & Yin et al., 2003 & AY379745 \\
\hline
\end{tabular}

random stepwise-addition of 10 replicates each and a branch-swapping algorithm of tree-bisectionreconnection (TBR) and ignoring the uninformative sites. For the data set we run parsimony analyses on all charters unweighted or differentially weighting transitions and transversions (TS/TV=4:5). We run MrBayes3_0b4 with the following specifications: The analysis was performed using the general timereversible model (GTR) including estimation of invariant sites with a gamma distribution (invgamma). Initial runs were conducted starting 400,000 generations starting with a random tree and employing 4 simultaneous MCMC chains was executed. Every 100th tree was saved into a file.

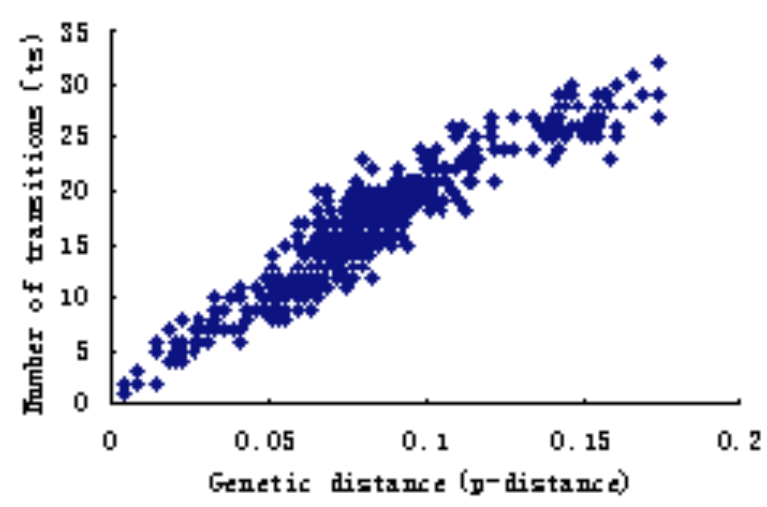

\section{RESULTS}

\subsection{Description of Data}

The sequences of the fifteen species studied by us have deposited in GenBank (accession numbers are showed in Table 1). The 16S rDNA data sets used for analyses contain 408 aligned sites, Of these sites, 135 were variable sites, 41 were parsimony informative. The average base composition are A: $32.5 \%, \mathrm{~T}: 35.7 \%$, G: $12.4 \%$ and C: $19.5 \%$, with the $A+T$ contents higher than those of $\mathrm{G}+\mathrm{C}$.

Patterns of substitutions among the 30 grasshoppers are shown in Figure 1. At or near the

Figure 1: Plots of genetic ( $p$-distance) against number of the transition and the transvertions. 


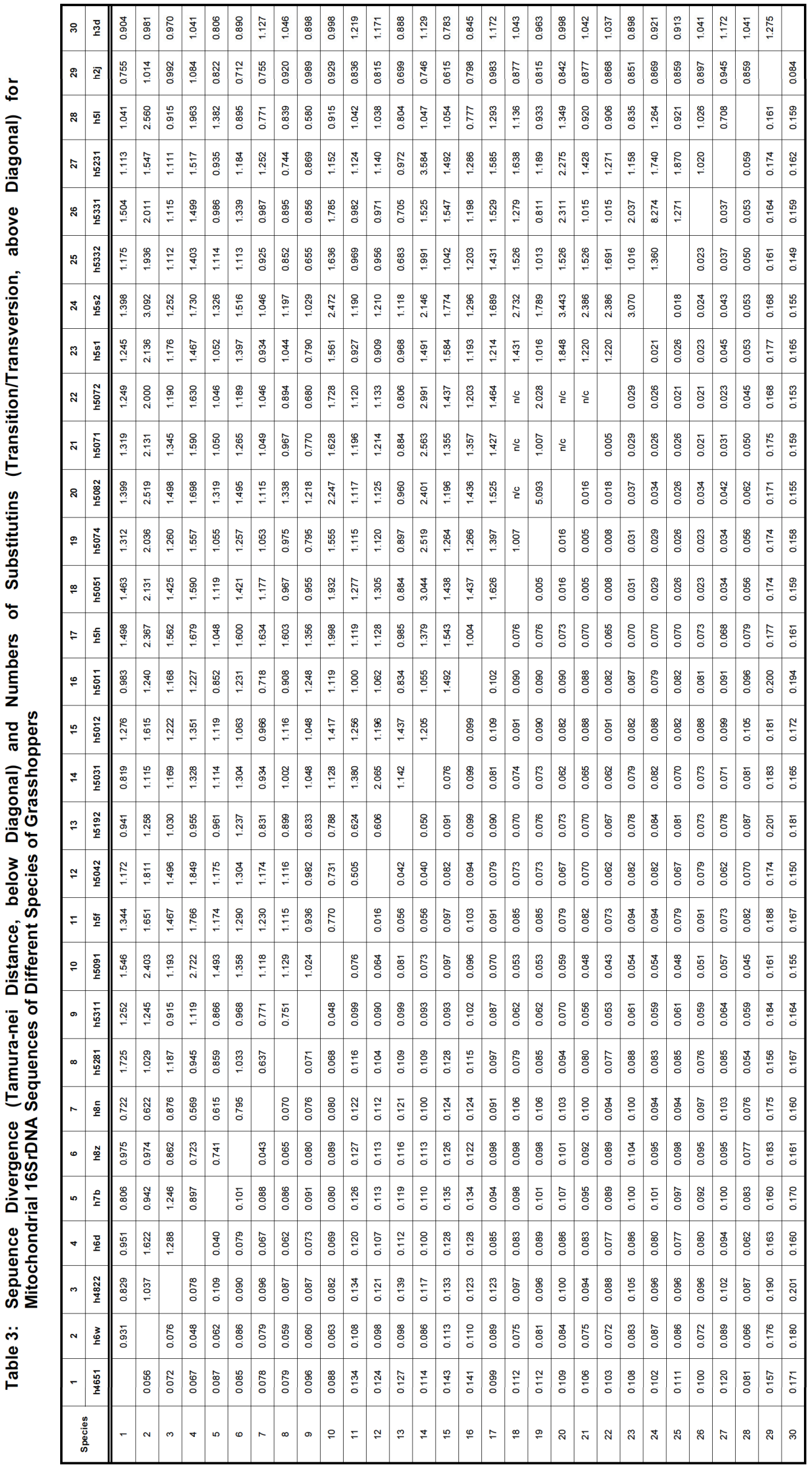


Table 4: Nucleotide Substitution Model Parameter Estimates for Two Indepemdent Bayesian Analyses, Upper Values in each Pair Correspond to Analyses A, Lower Values Correspond to Analyses B

\begin{tabular}{|c|c|c|c|c|}
\hline Parameter & Mean & Variance & \multicolumn{2}{|c|}{ 95\% Credibe Interval } \\
\hline Total tree length(TL) & 2.086719 & 0.126973 & 1.629000 & 2.792000 \\
\hline \multirow[t]{2}{*}{ Rate of substitutionr $R_{G T}$} & 1.000000 & 0.000000 & 1.000000 & 1.000000 \\
\hline & 1.000000 & 0.000000 & 1.000000 & 1.000000 \\
\hline Rate of substitutionr $R_{C T}$ & 3.444560 & 1.279798 & 1.602340 & 5.991721 \\
\hline \multirow[t]{2}{*}{ Rate of substitutionr $R_{C G}$} & 0.519617 & 0.108941 & 0.124913 & 1.391495 \\
\hline & 0.518451 & 0.075186 & 0.149706 & 1.191387 \\
\hline Rate of substitutionr $R_{A T}$ & 2.211812 & 0.380806 & 1.260839 & 3.720657 \\
\hline \multirow[t]{2}{*}{ Rate of substitutionr $R_{A C}$} & 0.237770 & 0.029756 & 0.016618 & 0.710178 \\
\hline & 0.232991 & 0.023969 & 0.057124 & 0.665314 \\
\hline \multirow[t]{2}{*}{ Base frequencies $\pi(A)$} & 0.321654 & 0.000408 & 0.283371 & 0.360295 \\
\hline & 0.320725 & 0.000375 & 0.282883 & 0.359047 \\
\hline \multirow[t]{2}{*}{ Base frequencies $\pi(C)$} & 0.109170 & 0.000235 & 0.081104 & 0.138288 \\
\hline & 0.108955 & 0.000199 & 0.084024 & 0.136404 \\
\hline \multirow[t]{2}{*}{ Base frequencies $\pi(G)$} & 0.188330 & 0.000263 & 0.156357 & 0.220288 \\
\hline & 0.187804 & 0.000275 & 0.157418 & 0.220808 \\
\hline
\end{tabular}

Bharat Book Bureau. Cell-based Assays: Technologies and Global Markets. http://robotics.tmcnet.com/news/2011/12/29/6022837.htm

$10 \%$ value TS began to level off, indicating saturation of TS. Nucleotide variation and substitution patterns were examined using the software package MEGA 6 (Table 3). The average value of TS/TV is 1.268 , and TS is a little higher than TV. The average value of the sequence divergence is 0.090 after the correction of Tamura-nei model.

\subsection{Phylogenetic Relationships}

Three phylogenetic trees, weighted MP tree (wMP tree), Neighbor-Joining (NJ) tree and Bayesian tree (Figures 2-4), were reconstructed. The structure of these phylogenetic trees are similar, and the grasshoppers of the Oedipodidae are clustered into one clade except Trilophidia annulata. In both MP and
$\mathrm{NJ}$ trees, the species studied can be clearly classified into five clades as follows: Clade I contains nine species: Bryodema luctuosum indum, Bryodema gansuensis, and Angaracris rhodopa (Bryodeminae); Bryodemilla diamesum and Bryodemella xizangensis (Bryodemellinae); and Celes akitanus, Sphingonotus salinus, Sphingonotus ningsianus, Sphingonotus haitensis, and Sphingonotus fuscoirroratus (Oedipodinae). Clade II contains six species: locusta migratory, Locusta migratoria manilensis, Gastrimargus marmoratus, Pternoscirta sauteri, and Pternoscirta pulchripes (Locustinae); Oedaleus decorus asiaticus, and Oedipoda coerulescens (Oedipodinae). Clade III consists of two species, Parapheurus alliaceus and Epacromius coerulies (Oedipodinae). Clade IV consists 
of only one species Aiolopus thalassinus. Clade V contains eight species: Chondracris rosea rosea, Xenocatantops humilis, Arcyptera fusca, Chorthippus intermedius, Dasyhippus peipingensis, Acrida cinerea, Acrida turrita, and Trilophidia annulata. The difference between wMP tree and NJ tree is mainly showed within the Clade I: Celes akitanus cluster with the grasshoppers of the subfamilies Bryodeminae and Bryodemellinae, and at the root of the wMP tree; Bayesian tree is different from the other two trees, as in the Bayesian tree Parapheurus alliaceus and Epacromius coerulies do not cluster with each other, and Trilophidia annulata is at the root ofthe tree.

\section{DISCUSSION}

\subsection{Characteristics of $16 \mathrm{~S}$ rDNA Sequence}

The average base composition in this study are $\mathrm{A}$ : $32.5 \%, \mathrm{~T}: 35.7 \%, \mathrm{C}: 12.4 \%$ and $\mathrm{G}: 19.5 \%$, with $\mathrm{A}+\mathrm{T}$ contents $(68.2 \%)$ higer than these of $C+G(31.9 \%)$, a pattern that has been seen repeatedly in the mtDNA of insects $[7,10,18]$. The number of transition is a little than those of transversion (TS/TV=1.268), which is different from the result of our previous study in the family Catantopidae (TS/TV=0.723) (unpublished). The grasshoppers of the Oedipodidae collapsed into one clade except $T$. annulata. However, in our previous study [8], the species of the Catantopidae clustered with the species of other families alternately. To some extent, the results suggested that the species within the Catantopidae are more divergent than those within the Oedipodidae.

\subsection{Monophyly of the Oedipodidae}

According to the most taxonomic systems, the grasshoppers of the Oedipodidae are classified as a subfamily Oedipodinae of the family Acrididae [5,6], and it consistent with the Orthoptera Species File Online at internet [19].

All the phylogenetic trees did not support the monophyly of the Oedipodidae, because $T$. annulata did not cluster with the rest grasshoppers analysed in this study. NJ tree and wMP tree suggested that the Oedipodidae is a polyphyly, while Bayesian tree suggested it is paraphyletic. All these relationships are well supported (pp 1.0 on the Figures 2-4). Considering the previous study on the Acrididae based on $18 \mathrm{~S}$

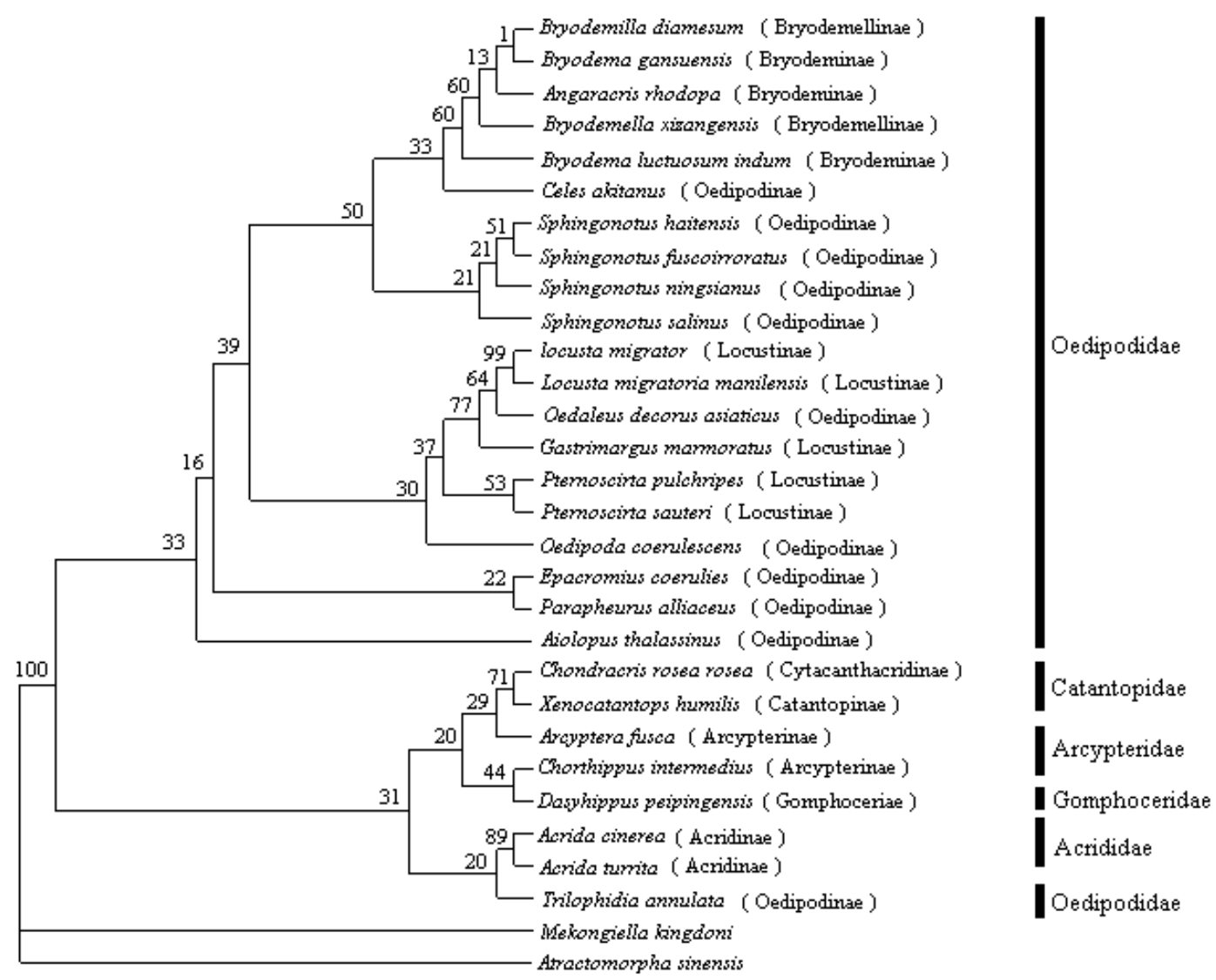

Figure 2: The maximum parsimony tree of weighting 4:5 for ts:tv resulting from analysis of the $16 \mathrm{~S}$ rDNA sequences of 30 grasshoppers. (Number on nodes correspond to percentage bootstrap values for 1000 replicates). 


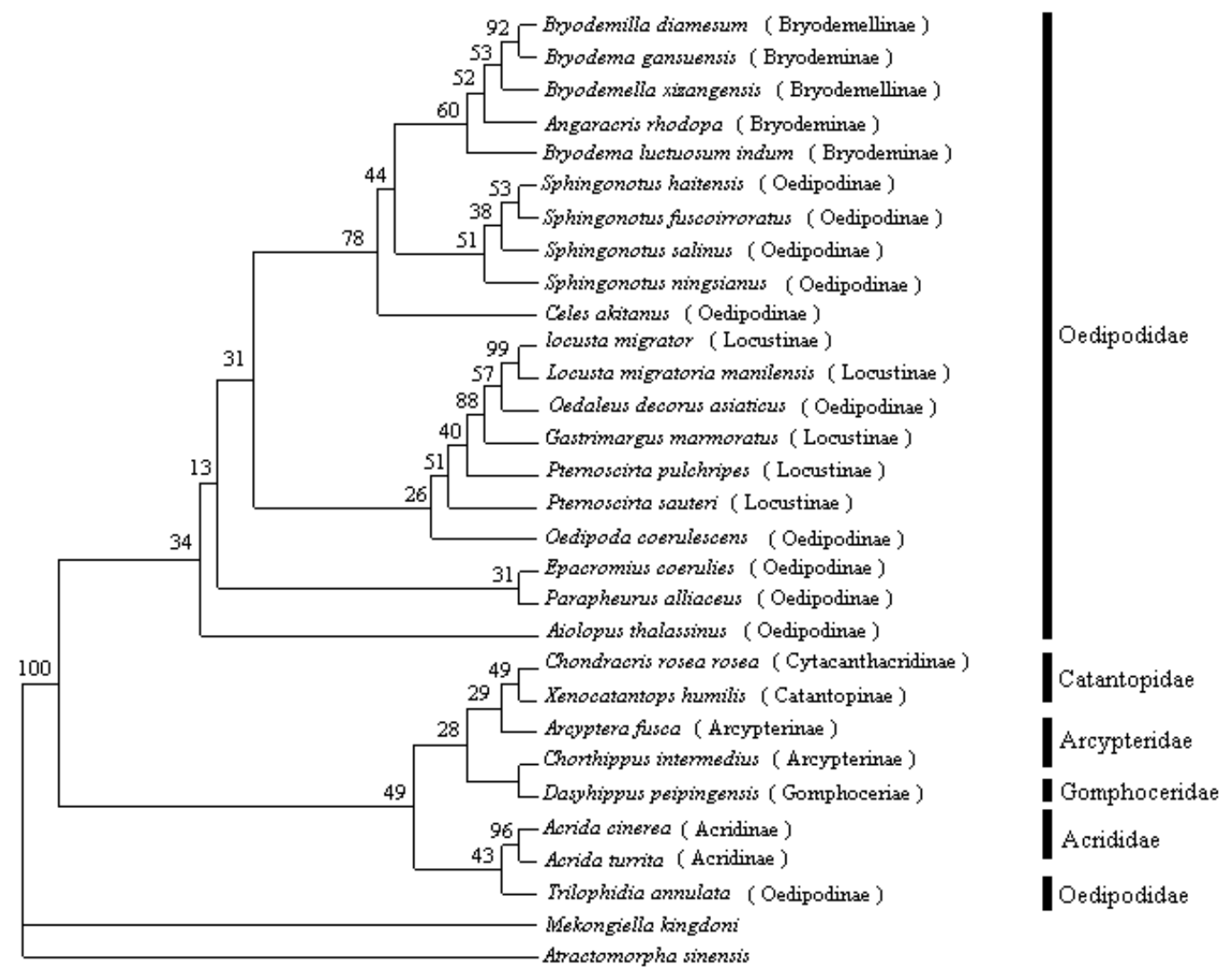

Figure 3: The neighbor-joining tree resulting from analysis of the $16 \mathrm{~S}$ rDNA sequences of 30 grasshoppers. (Number on nodes correspond to percentage bootstrap values for 1000 replicates).

rDNA [8], we therefore suggested that the grasshoppers of the Oedipodinae should be classified as one subfamily of the Acrididae, but the taxonomic positions of some species need further study.

\subsection{The Taxonomic Positions of Bryodeminae and Bryodemellinae}

The species of the geus Bryodemella has sometimes been treated as one of the genus Bryodema based on some morphological characters before Yin [3]. The distinguishable morphological characters in Bryodemella are, 1) Elytron with no intercalary vein in medial area; if some times with a weak one, then not serrated. 2) Dorso external carinae of hind femur finely serrated in terminal half, stridulated with thicken longitudinal veins of hindwing. The genus Bryodemella was further elevated to a new subfamily, i.e. Bryodemellinae, based on stridulatory apparatus of some gasshoppers in Yin [3]. The three phylogenetic trees in our study showed that the species of the Bryodeminae (Bryodema gansuensis, Bryodema luctuosum indum, Angaracris rhodopa) clustered with those of Bryodemellinae (Bryodemilla diamesum, Bryodemella xizangensis), which suggested that the two subfamilies were closely related; and the phylogentic analysis did not support the monophyly of the genera Bryodemella, Bryodema and Angaracris, and therefore further proved the invalidity of the subfamily Bryodemellinae.

\subsection{Phylogenetic relationships within Oedipodidae}

The family Oedipodidae is separated into four subfamilies based on some following morphological characters: dorsal carina of hind femur, and elytron with intercalary vein in medial area and main longitudinal veins of hindwing. The four subfamilies are Locustinae, Bryodemellinae, Bryodeminae and Oedipodinae [3]. But our results did not support the division of the four subfamilies. First, phylogenetic analyses did not support the basic status of the subfamily Bryodemellinae, wMP tree and Baysian trees showed that those species of Bryodemellinae and Bryodeminae firstly cluster with each other, then they cluster with Celes akitanus of the subfamily Oedipodinae, so the monophyly of the subfamily Bryodeminae is not supported in our study, and thus further study is necessary. Second, our phylogenetic analyses did not support the monophyly of the subfamilies Locustinae and Oedipodinae. The species of the Locustinae and some species of the 


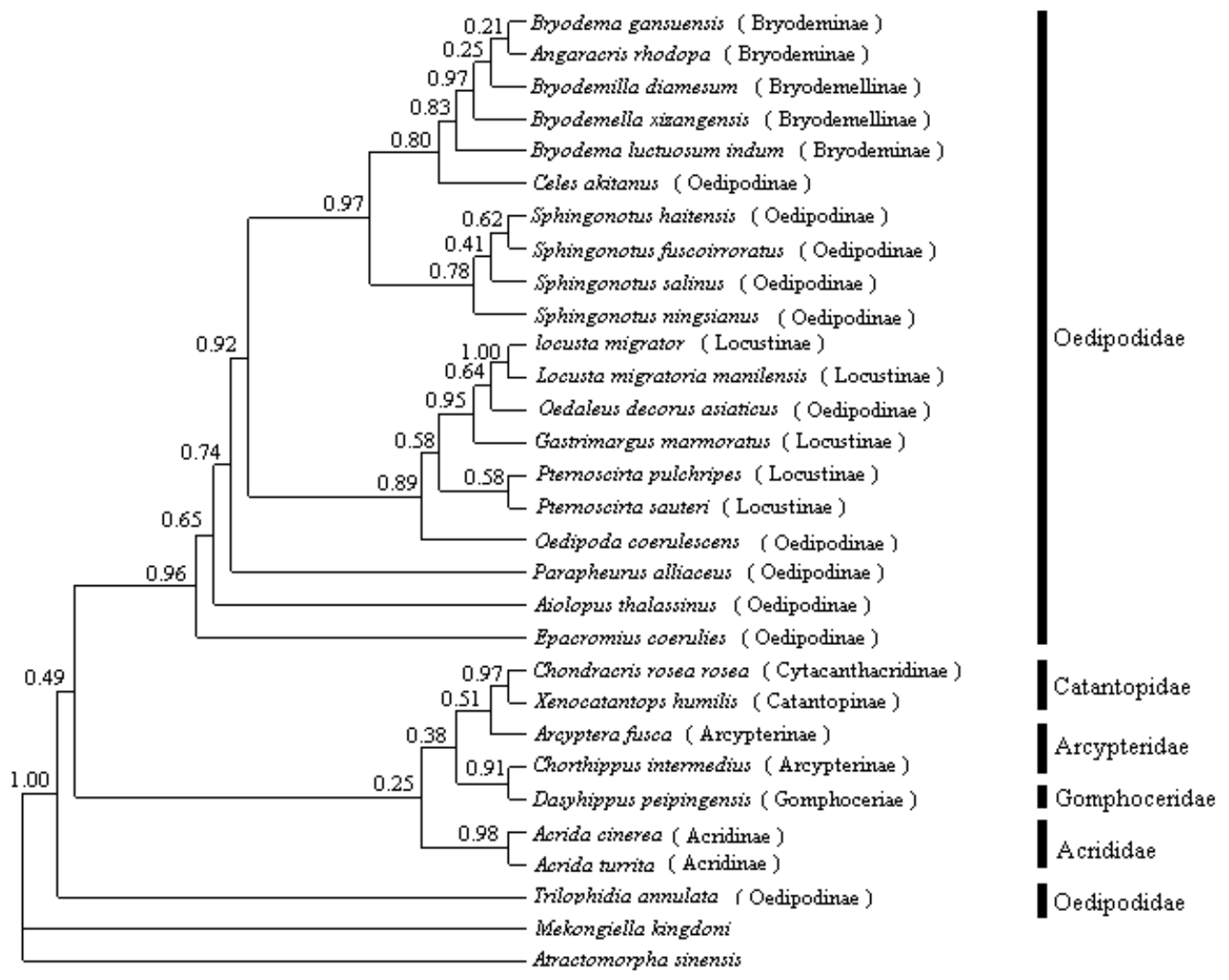

Figure 4: The bayesian tree resulting from analysis $16 \mathrm{~S}$ rDNA sequences of 30 grasshoppers. (Number on nodes correspond to the values of posterior probability values).

Oedipodinae gathered with each other, the former clade is composed of Locusta migratory, Locusta migratoria manilensis, Gastrimargus marmoratus, Pternoscirta sauteri, Pternoscirta pulchripes; the latter is composed of Oedaleus decorus asiaticus, Oedipoda coerulescens. In addition, rest species of the Oedipodinae forms one clade.

C - banding karyotype and the nucleolar organizer region with silver impregnation have been analyzed to eight species of six genera of the Odipodidae [20]. Our results suggested these six generacan be divided into three groups based on their relationships resulting from our analyses. The genus Locusta is close related to Gastrimargus, together forming a group; there are close relationships among Epacromius, Aiolopus and Oedaleus; the genus Angaracris is divergent from the former two groups, independently forming a group.

\section{ACKNOWLEDGEMENTS}

We would like to thank Jian-Wen Liu and BingZhong Ren for collecting some specimens. This work was supported by grants from the National Natural Sciences Foundation of China (No. 30970339) to GuoFang Jiang, Nanjing Normal University Innovative
Team Project (No. 0319PM0902), and A Project Funded by the Priority Academic Program Development of Jiangsu Higher Education Institutions.

\section{REFERENCES}

[1] Jiang GF, Zheng ZM. Grasshoppers and Locusts from Guangxi. Guangxi Normal University Press, China 1998.

[2] Zheng ZM, Xia KL. Fauna Sinica, Insecta Vol. 10.Orthoptera: Acridoidea (Oedipodidae and Arcypteridae). Beijing: Science Press 1998.

[3] Yin XC. Grasshoppers and locusts from Qingzang Altiplano. Beijing: Science Press 1984.

[4] Uvarov BP. Grasshoppers and locusts, vol. 1. Cambridge University Press, London 1966.

[5] Dirsh VM. Classification of the Acridomorphoidea Insects Classey, Farringdon, Oxford 1975.

[6] Vickery VR, Kevan DKM. A monograph of the Orthopteroid insects of Canada and adjacent regions. Vol. I-II. Lyman Ent. Museum and Res. Lab. Memoir, No. 13. 1983.

[7] Flook PK, Rowell CHF. The Phylogeny of the Caelifera (Insecta, Orthoptera) as Deduced from mtrRNA Gene Sequences. Mol Phylogenet Evol 1997; 8(1): 89-103. http://dx.doi.org/10.1006/mpev.1997.0412

[8] Liu DF, Jiang GF. Molecular phylogenetic analysis of Acridoidea based on 18S rDNA with a discussion on its taxonomic system. Acta Entomologica Sinica 2005; 48(2): 232-241.

[9] Wang BX, Yang LF. Phylogenetic utilites of mitochondrial DNA sequences in the study of insect systematics. Entomological Knowledge 2002; 39(2): 88-92. 
[10] Yin $H$, Zhang DC, Yin Zh, Liu Y, Yin XC. Molecular phylogeny of some species of the Acridoidea based on $16 \mathrm{~S}$ rDNA. Acta Genetica Sinica 2003; 30(8): 766-772.

[11] Xia KL. Fauna Sinica, Insecta Vol. 4, Orthoptera. Acridoidea, Pamphagidae, Chrotogonidae, Pyrgomorphidae. Beijing: Science Press 1994.

[12] Sambrook J, Fritsch EF. Molecular Cloning: A Laboratory Manual.Cold Spring Harbor Laboratory 1989.

[13] Simon C, Frati F, Beckenbach A, Crespi B, Liu H, Flook P. Evolution, weighting and phylogenetic utility of mitochondrial gene sequences and a compilation of conserved PCR primers. Ann Entomol Soc Am 1994; 87: 651-701.

[14] Thompson JD, Gibson TJ, Plewniak F, Jeanmougin F, Higgins DG. The Clustal $X$ windows interface: Flexible strategies for multiple sequence alignment aided by quality analysis tools. Nucleic Acids Research 1997; 24: 4876-4882. http://dx.doi.org/10.1093/nar/25.24.4876

[15] Tamura K, Stecher G, Peterson D, Filipski A, Kumar S. MEGA6: Molecular Evolutionary Genetics Analysis Version 6.0. Molecular Biology and Evolution 2013; 30: 2725-2729. http://dx.doi.org/10.1093/molbev/mst197
[16] Swofford DL. Phylogenetic Analysis Using Parsimony and other methods, Version 4. Sunderland, MA: Sinauer Associates 1998.

[17] Huelsenbeck, JP, Ronquist F. MRBAYES: Bayesian inference of phylogenetic trees. Bioinformatics 2001; 17 : 754-755.

http://dx.doi.org/10.1093/bioinformatics/17.8.754

[18] Flook PK, Klee S, Rowell CHF. Combined molecular phylogenetic analysis of the orthoptera (Arthropoda, Insecta) and implications for their higher systematics. Syst Biol 1999; 48(2): 233-253. http://dx.doi.org/10.1080/106351599260274

[19] Eades DC, Otte D, Cigliano MM, Braun H. Orthoptera Species File Online 2014. Version 5.0/5.0. Available from: http://Orthoptera.Species File.org/ (accessed 10 Oct 2014).

[20] Jia LX, Ma EB. Cytotaxonomic study of some species and genera in Odipodidae. Journal of Shannxi University (Nat. Sci. Ed.). 1998; 21(3): 291-296.

Received on 03-09-2014

Accepted on 13-10-2014

Published on 15-10-2014

DOI: http://dx.doi.org/10.6000/1927-3037.2014.03.03.4

(C) 2014 Liu and Jiang; Licensee Lifescience Global.

This is an open access article licensed under the terms of the Creative Commons Attribution Non-Commercial License (http://creativecommons.org/licenses/by-nc/3.0/) which permits unrestricted, non-commercial use, distribution and reproduction in any medium, provided the work is properly cited. 